\title{
MEASUREMENTS OF THE OXALIC ACID II/OXALIC ACID I RATIO AS A QUALITY CONTROL PARAMETER AT NOSAMS
}

\author{
R. J. SCHNEIDER, A. P. MCNICHOL, M. J. NADEAU and K. F. VON REDEN \\ National Ocean Sciences AMS Facility, Woods Hole Oceanographic Institution, Woods Hole \\ Massachusetts 02543 USA
}

\begin{abstract}
Precision of AMS single-target measurements is usually based on counting statistics and variance during the data acquisition cycle. Additional longer-term variability may be studied by looking at the variability of the standards from
cycle to cycle.
\end{abstract}

\section{INTRODUCTION}

The most commonly used standards for determining the fraction-modern in accelerator mass spectrometry (AMS) measurements are NIST Oxalic Acid I (HOxI) (SRM 4990B, prepared from beet sugar in 1958) and Oxalic Acid II (HOxII) (SRM 4990C, prepared in 1974). ${ }^{1}$ Both materials have well-established concentrations of carbon 13 and carbon 14 . The ratio between the ${ }^{14} \mathrm{C}$ concentrations of the two oxalic acid standards is 1.293 (Stuiver 1983) and the behavior of their $\delta^{13} \mathrm{C}$ for each carousel of 58 samples has been used to compare the performance of both Woods Hole sputter ion source injectors. Differences in sputter efficiency and emittance can affect the measured isotopic ratios. In many cases, a linear relation is seen between the isotope shifts for ${ }^{14} \mathrm{C}$ and ${ }^{13} \mathrm{C}$, and the data can then be corrected for system fractionation. By studying the time variations in the isotopic ratios, the stability of the AMS system as a whole can be assessed. A general time series analysis of AMS data has enabled us to minimize the variance in repeated measurements on the same graphite sample to three parts per mil. At this level, it should then be possible to separate these errors from the variability due to sample processing.

\section{METHODS}

By comparing the measured ratios of ${ }^{14} \mathrm{C} /{ }^{12} \mathrm{C}$ to those expected from the literature on oxalic acid, we can estimate the AMS detection efficiency for ${ }^{14} \mathrm{C}$ relative to ${ }^{12} \mathrm{C}$. For AMS systems of the Woods Hole type (von Reden et al. 1994), also found at Groningen and Kiel (manufactured by High Voltage Engineering Europa, Amersfoort, The Netherlands) the ${ }^{12} \mathrm{C}$ and ${ }^{13} \mathrm{C}$ beams are measured in Faraday cups following the $110^{0}$ spectrometer magnet. The ${ }^{14} \mathrm{C}$ must then pass through additional analysis. The relative detection efficiency of ${ }^{14} \mathrm{C}$ to ${ }^{12} \mathrm{C}$ is the product of several factors, including the transmission of the final analysis leg, the relative stripping and sputter efficiencies for the two isotopes, and the collection efficiency of the ${ }^{14} \mathrm{C}$ ionization chamber.

Much has been written on HOxI (the "old" oxalic acid). Its activity in 1950 was quoted by Karlen $e t$ al. (1964) as $14.27 \mathrm{dpm} \mathrm{g}^{-1}$-carbon. The absolute ratio of ${ }^{14} \mathrm{C} /{ }^{12} \mathrm{C}$ for that year was therefore 1.250 $\times 10^{-12}$ (with a $1 \%$ uncertainty). To date, it has decayed to $1.243 \times 10^{-12}$. If we assume that no fractionation occurs during sample preparation, then we would expect to be able to measure an isotopic ratio by AMS that differs from this value only by an efficiency factor.

Because of small variations in machine tuning that also affect the measured isotope ratio, we have been plotting the slope of the ${ }^{14} \mathrm{C} /{ }^{12} \mathrm{C}$ ratio against $\delta^{13} \mathrm{C}$ for the standards on each wheel of samples. (This is a linear effect, in contrast to the natural or Rayleigh fractionation, which is quadratic in

${ }^{1}$ These two standards were formerly designated as NBS OxI and NBS OxII. 
mass.) Fortunately for AMS, the samples and standards are affected equally, so that the fractionsmodern are only slightly affected. If we correct our measured isotope ratio to the book value for $\delta^{13} \mathrm{C}$, the equation is

$$
\left[\frac{\mathrm{C}}{{ }^{12} \mathrm{C}}\right]_{\mathrm{m}}=\left[\frac{{ }^{14} \mathrm{C}}{{ }^{12} \mathrm{C}}\right]_{\mathrm{b}} \mathrm{E}_{\mathrm{r}}(1-\text { Slope } \cdot \text { Shift })
$$

where Shift refers to the difference between the AMS measured value of the ${ }^{13} \mathrm{C} /{ }^{12} \mathrm{C}$ ratio from the book value for the oxalic acid. Slope is obtained from a straight-line fit and varies slightly from carousel to carousel, depending on the tuning of the AMS system. Figure 1 shows a summary of all the HOxI measurements made during 1993 . The relation between $\delta^{14} \mathrm{C}$ and $\delta^{13} \mathrm{C}$ shows good linearity and nearly unit slope. This means that a $1 \%$ change in $\delta^{13} \mathrm{C}$ is associated with a $1 \% 0$ change in $\delta^{14} \mathrm{C}$. Because the ${ }^{13} \mathrm{C} /{ }^{12} \mathrm{C}$ ratio is used as a tuning parameter, the shifts were normalized to the mean for each carousel. For a recent carousel, the slope was 0.0015 and a typical shift was 0.006 (6\%o) below the book value. The fit gave a value for ${ }^{14} \mathrm{C} /{ }^{12} \mathrm{C}$ of $1.090 \times 10^{-12}$, when corrected to the $\delta^{13} \mathrm{C}$ value of $-19.28 \%$. Equation (1) then yields a relative efficiency $E_{r}$ of 0.877 . Using the same method for HOxII gives an $E_{\mathrm{r}}$ of 0.871 .

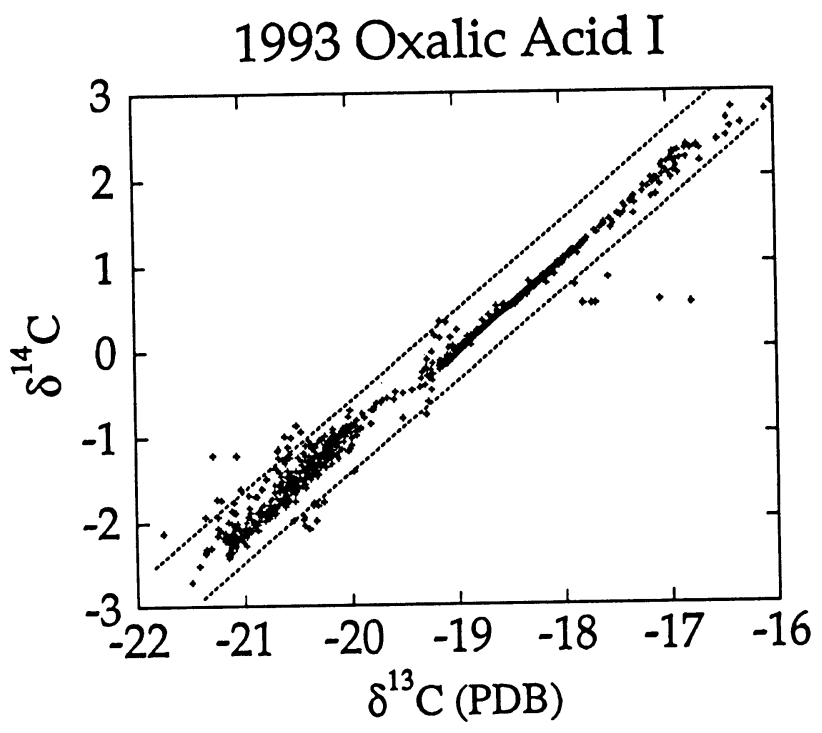

Fig. $1 . \delta^{14} \mathrm{C}$ plotted vs. $\delta^{13} \mathrm{C}$ for all measurements on HOxI made during 1993. Because the ${ }^{13} \mathrm{C} /{ }^{12} \mathrm{C}$ ratio is used as an AMS system tuning parameter, the operator attempts to maintain a constant value throughout data acquisition. Good linearity was maintained by not cratering the graphite targets appreciably.

This result turns out to be very close to the ratio of the calculated stripping efficiencies at $2.5 \mathrm{MeV}$. These are $47 \%$ for ${ }^{14} \mathrm{C}$ and $53 \%$ for ${ }^{12} \mathrm{C}$, or a ratio of 0.89 . Taking errors into account, we can say that the relative detection efficiency of ${ }^{14} \mathrm{C}$ to ${ }^{12} \mathrm{C}$ is better than $95 \%$.

Repeated single-target measurements are limited by target life, but usually 6-10 exposures of 300 sec for each graphite target are possible. These take place over the two-day run for a typical carousel of samples. The ${ }^{14} \mathrm{C}$ counting statistics have been verified to be Gaussian (Jirikowic et al. 1994) and the variance among the several target exposures agrees with a Student's $\mathrm{T}$ distribution for small numbers of trials. For 8-10 trials, the expected number of results beyond $3 \sigma$ from the mean are $0.3 \%$ for Gaussian and $1.6 \%$ for Student's T; the expected number beyond $2 \sigma$ are $5 \%$ for Gaussian 
and $8 \%$ for Student's T. As the number of trials increases, the two distributions would become closer, but generally 30 or more AMS measurements on a single target are impractical. Standard measurement procedures at the National Ocean Sciences AMS Facility (NOSAMS) (Schneider et al. 1994) yield precisions of 5\%o or less for typical seawater and marine samples. We quote the larger of 1) the standard error or 2) the propagated internal statistics as our precision. This practice is common to many AMS laboratories (Currie 1994). A typical breakdown of the contributions to the total error is: counting statistics (sigma) 3.5\%; AMS system stability $2.0 \%$; sample processing $2.5 \%$; $\delta^{13} \mathrm{C}$ correction $1.0 \%$. These add in quadrature to $4.8 \%$.

By studying the variation of the standards from wheel to wheel, we can obtain some idea of the longterm reproducibility. We typically make 30 measurements each of the two standards during the course of a data acquisition cycle. These are spread over several different targets, but the graphites are all derived from the same flasks of $\mathrm{CO}_{2}$ made from each standard. The measured ${ }^{14} \mathrm{C} /{ }^{12} \mathrm{C}$ ratios of the HOxI (corrected to $-19.28 \%$ ) and HOxII (corrected to $-17.68 \%$ ) standards may slowly vary from month to month, but their ratio has stayed quite close to the value of 1.293 , with a relative standard deviation of $6 \%$. The $\delta^{13} \mathrm{C}$ values are measured on a VG Prism mass spectrometer and average $-19.28 \%$ and $-17.68 \%$, respectively, with a standard deviation of $0.02 \%$. Figure 2 shows how the ratio has fluctuated with each sample carousel during the first half of 1994; results indicate no systematic difference in results taken with either ion source or recombinator. When it is necessary to prepare a new batch of either standard, we sample the gas for $\delta^{13} \mathrm{C}$ analysis and monitor the ${ }^{14} \mathrm{C}$ concentrations to make sure that they are within the above tolerances.

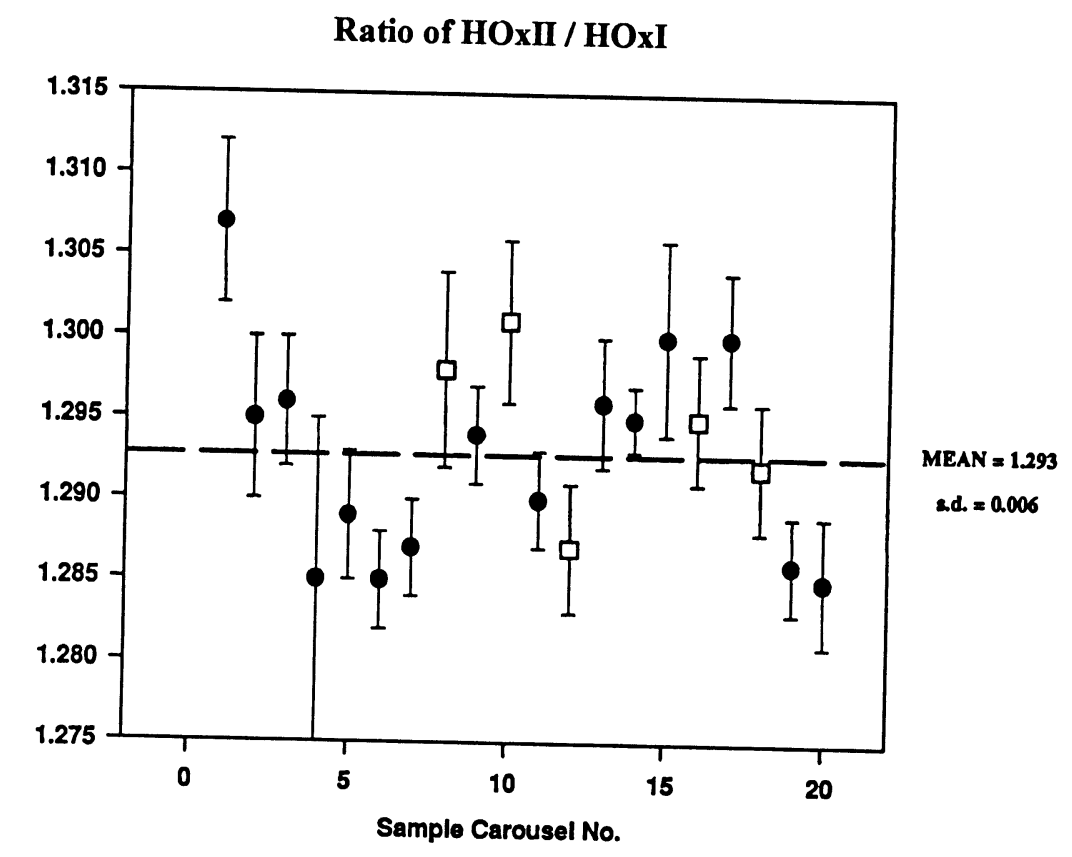

Fig. 2. Variation of the ratio of HOxII to HOxI for the first 20 sample carousels measured during 1994. The mean value of 1.293 equals the expected ratio,; standard deviation is 0.006 . $\bullet=$ carousels run on the first injector; $\square=$ carousels run on the second injector, as it was phased into routine operation. 
We use both standards interchangeably, with the constraints in our data analysis program that HOxI is 1.052 modern and HOxIl is 1.36 modern. We frequently analyze the data from a carousel of samples first with HOxI fixed, then with HOxII fixed, and a third time with both values constrained. By optimizing the chi-squares of these data sets, we find that the differences in the sample results at 0.8 modern are $c a .4 \%$, which is comparable with the internal precision.

The accuracy of AMS measurements depends ultimately upon the definition of the standards used for comparison. Because most AMS samples have ${ }^{14} \mathrm{C} /{ }^{12} \mathrm{C}$ ratios that are less than modern, it is unfortunate that both of the primary standards are at one extreme end of the range of interest. The uncertainty in ${ }^{14} \mathrm{C}$ concentration for HOxI and HOxII is $1 \%$. With the recent availability of the IAEA suite of samples and their consensus values (Rozanski et al. 1992), an assessment can be made of the accuracy or bias of a given laboratory's results over the entire range of ${ }^{14} \mathrm{C}$ ages. Although NOSAMS was not ready to participate in this study, we measured the set of six IAEA samples in late 1992. We obtained an average precision of 5\%o and an average deviation from the consensus values of $5 \%$. Our accuracy was thus $c a .7 \%$. We have participated in the TIRI intercomparison (Scott $e t$ al. 1994). It is important for all laboratories to repeat these external calibrations at regular intervals to verify quality control.

\section{CONCLUSION}

Routine internal monitoring of the HOxI to HOxII ratio from sample carousel to sample carousel provides a short-term check on quality. It can also reveal variations when new batches of standards are produced.

\section{ACKNOWLEDGMENTS}

We are indebted to E. Osborne, G. Cohen, A. Gagnon and D. Hutton for the careful preparation of standards and graphite targets. Overall quality control of AMS data and reporting has been monitored by K. Elder. This work is supported by NSF grant OCE-930101500, and represents WHOI contribution number 9033 .

\section{REFERENCES}

Currie, L. A. 1994 Optimal estimation of uncertainty intervals for acceleration and decay counting. Nuclear Instruments and Methods in Physics Research B 92: 188-193.

Jirikowic, J. L., Schneider, R. J., von Reden, K. F. and Jones, G. A. 1994 (ms.) Do AMS measurements approach a Gaussian distribution? Poster presented at the 15 th International ${ }^{14} \mathrm{C}$ Conference, Glasgow, Scotland, 15-19 August.

Karlen, I., Olsson, I. U., Kallberg, P. and Kilicci, S. 1964 Absolute determination of the activity of two ${ }^{14} \mathrm{C}$ dating standards. Arkiv for Geofysik 4(22): 465-471.

Rozanski, K., Stichler, W., Gonfiantini, R., Scott, E. M., Beukens, R. P., Kromer, B. and van der Plicht, J. 1992 The IAEA intercomparison exercise 1990. In Long, A. and Kra, R.S., eds., Proceedings of the 14th International ${ }^{14} \mathrm{C}$ Conference. Radiocarbon 34(3): 506-519.

Schneider, R. J., Jones, G. A., McNichol, A. P., von Reden, K. F., Elder, K. L., Huang, K. and Kessel, E. D.
1994 Methods for data screening, flagging and error analysis at the National Ocean Sciences AMS facility. Nuclear Instruments and Methods in Physics Research $B$ 92:172-175.

Scott, E. M., Harkness, D. D., Cook, G. T., Miller, B. F., Begg, F. H. and Holton, L. (ms.) 1994 The TIRI Project: A Status Report. Paper presented at the 15th International ${ }^{14} \mathrm{C}$ Conference, Glasgow, Scotland, 1519 August.

Stuiver, M. 1983 International agreements and the use of the new oxalic acid standard. In Stuiver, M. and Kra, R.S., eds., Proceedings of the 11 th International ${ }^{14} \mathrm{C}$ Conference. Radiocarbon 25(2): 793-795.

von Reden, K. F., Schneider, R. J., Cohen, G. J. and Jones, G. A. 1994 Performance characteristics of the 3 MV Tandetron AMS system at the National Ocean Sciences AMS facility. Nuclear Instruments and Methods in Physics Research B 92:7-11. 